\title{
Removal of pharmaceuticals in WWTP effluents by ozone and hydrogen peroxide
}

\author{
G Hey', SR Vega ${ }^{2}$, J Fick', M Tysklind ${ }^{3}$, A Ledin', J la Cour Jansen'* and HR Andersen ${ }^{4}$ \\ 'Water and Environmental Engineering, Department of Chemical Engineering, Lund University, PO Box 124, 22100 Lund, Sweden \\ 2Departamento de Ingenieria Química, Facultad de Ciencias Químicas, Complutense University, Madrid, 28040, Spain \\ ${ }^{3}$ Department of Chemistry, Umeå University, 90187 Umeå, Sweden \\ ${ }^{4}$ Department of Environmental Engineering, Technical University of Denmark, Miljøvej, Building 113, 2800 Kongens Lyngby, Denmark
}

\section{ABSTRACT}

Ozonation to achieve removal of pharmaceuticals from wastewater effluents, with $\mathrm{pH}$ values in the upper and lower regions of the typical range for Swedish wastewater, was investigated. The main aim was to study the effects of varying $\mathrm{pH}$ values (6.0 and 8.0), and if small additions of $\mathrm{H}_{2} \mathrm{O}_{2}$ prior to ozone treatment could improve the removal and lower the reaction time. The effluents studied differed in their chemical characteristics, particularly in terms of alkalinity $\left(65.3-427 \mathrm{mg} \cdot \ell^{-1}\right.$ $\left.\mathrm{HCO}_{3}^{-}\right), \mathrm{COD}\left(18.2-41.8 \mathrm{mg} \cdot \ell^{-1}\right)$, DOC (6.9-12.5 $\mathrm{mg} \cdot \ell^{-1)}$, ammonium content $\left(0.02-3.6 \mathrm{mg} \cdot \ell^{-1}\right)$ and specific UV absorbance $\left(1.78-2.76 \ell \cdot \mathrm{mg}^{-1} \cdot \mathrm{m}^{-1}\right)$. As expected, lower ozone decomposition rates were observed in the effluents at $\mathrm{pH} 6.0$ compared to $\mathrm{pH}$ 8.0. When $\mathrm{pH} 8.0$ effluents were ozonated, a higher degree of pharmaceutical removal occurred in the effluent with low specific UV absorbance. For pH 6.0 effluents, the removal of pharmaceuticals was most efficient in the effluent with the lowest organic content. The addition of $\mathrm{H}_{2} \mathrm{O}_{2}$ had no significant effect on the quantitative removal of pharmaceuticals but enhanced the ozone decomposition rate. Thus, $\mathrm{H}_{2} \mathrm{O}_{2}$ addition increased the reaction rate. In practice, this will mean that the reactor volume needed for the ozonation of wastewater effluents can be reduced.

Keywords: ozone; pharmaceuticals; hydrogen peroxide; wastewater effluents

\section{INTRODUCTION}

A number of pharmaceuticals of differing therapeutic class, along with their metabolites, have been detected in aquatic environments (Ternes, 1998; Kolpin et al., 2002; Fent et al., 2006; Batt et al., 2006; Snyder, 2008; Verlicchi et al., 2012). The major source of these pharmaceuticals is considered to be the discharge of effluents by wastewater treatment plants (WWTPs) that are not designed for removing trace organic pollutants, in view of the recalcitrance of such pollutants to biodegradation and their limited biological activity, especially in cold climates. Accordingly, additional treatment following biological treatment is called for.

Ozonation is one of the most promising technologies for the removal of organic micropollutants contained in wastewater. The efficiency of ozone in removing pharmaceuticals and personal care products, both from water generally and from wastewater, has been tested in both laboratory- and pilot-scale experiments (Ternes et al., 2003; Huber et al., 2005; Buffle et al., 2006a,b; Bahr et al., 2007; Benner and Ternes, 2009; Hollender et al., 2009; Hansen et al., 2010; Zimmermann et al., 2011). Ozone-based oxidation can be more energy-efficient than UV-based oxidation, especially when used for treatment of waters high in UV absorbance (Rosenfeldt et al., 2006; Hansen and Andersen, 2012).

One of the benefits of using ozonation in aqueous solutions is that the hydroxyl $(\mathrm{OH})$ radicals that are produced will

\footnotetext{
To whom all correspondence should be addressed.

+4iil 46462228999 ; Fax: +46 462224526

e-mail: jes.la_cour_jansen@chemeng.lth.se

Received 12 February 2013; accepted in revised form 17 December 2013.
}

react non-selectively with pharmaceuticals, which could be an advantage for those pharmaceuticals that are difficult to degrade by direct reaction with ozone (Lee and Von Gunten, 2010). The $\mathrm{OH}$ radicals are generated through the self-decomposition of ozone in water at $\mathrm{pH}$ levels above 7 , where the hydroxide ions are acting as initiators (Hoigne and Bader, 1983). Laboratory experiments have shown that the addition of hydrogen peroxide $\left(\mathrm{H}_{2} \mathrm{O}_{2}\right)$ enhances the decomposition of ozone, promoting the production of $\mathrm{OH}$ radicals (Von Gunten, 2003). Furthermore, non-selective oxidation by highly reactive radicals usually enhances the reaction rates of ozone-resistant compounds, which will reduce the treatment time required (Zwiener and Frimmel, 2000; Huber et al., 2003). Balcioglu and Ötker (2003) reported that adding $\mathrm{H}_{2} \mathrm{O}_{2}$ enhances both the UV absorbance (at $254 \mathrm{~nm}$ ) removal and the decrease of COD in wastewater. The rapid reaction of $\mathrm{OH}$ radicals is preferable in practice since it reduces the reactor size needed for such treatment. The efficiency of ozone treatment for the removal of pharmaceuticals can also depend upon the reactivity of the wastewater matrix in general (Nöthe et al., 2009).

The present study aimed at investigating the impact of varying $\mathrm{pH}$ levels, within the natural interval in Sweden $(\mathrm{pH}$ $6-8$ ), on the removal of pharmaceuticals from wastewater effluents by the addition of ozone. It also determined if the reactivity of ozone can be promoted by addition of small amounts of $\mathrm{H}_{2} \mathrm{O}_{2}$ at low $\mathrm{pH}$ levels. Since the addition of $\mathrm{H}_{2} \mathrm{O}_{2}$ can be expected to enhance the decomposition of ozone to $\mathrm{OH}$ radicals, it is of interest to investigate the effect this has in the case of effluents with a $\mathrm{pH}$ below 7 , where the reaction rate can be expected to be lower and the pharmaceutical removal rate lower due to the lack of hydroxide ions that promote the decomposition of ozone. 


\section{MATERIALS AND METHODS}

\section{Overall experimental setup}

Two effluents of relatively high $\mathrm{pH}(\mathrm{pH} 8.0)$ were treated with ozone, whereas two other effluents, low in $\mathrm{pH}$ ( $\mathrm{pH} 6.0$ ), were treated with ozone in combination with $\mathrm{H}_{2} \mathrm{O}_{2}$. Treatment was carried out at these $\mathrm{pH}$ levels since they correspond to the upper and lower range of $\mathrm{pH}$ values typically found in Swedish WWTP effluents. The effluents selected were from plants with extended nitrogen and phosphorus removal. The difference in $\mathrm{pH}$ is due to the origin of the potable water (ground versus surface waters). Further, the effluents also differ with respect to other chemical parameters such as alkalinity and ammonium and organic matter content. The pharmaceuticals investigated represent different therapeutic classes commonly used in Sweden, most of them having been found to be present in WWTP effluents (Falås et al., 2012).

The production of $\mathrm{OH}$ radicals by ozone decomposition was followed indirectly through measuring the ozone concentration. The experiments were carried out initially in effluents with a pH range between 6 and 8 , with the aim to determine the minimum amount of $\mathrm{H}_{2} \mathrm{O}_{2}$ needed to increase the decomposition of ozone.

\section{Chemicals}

The $\mathrm{H}_{2} \mathrm{O}_{2}$ solution (30\%) employed was purchased from SigmaAldrich, the $\mathrm{NaOH}$ and $\mathrm{H}_{2} \mathrm{SO}_{4}$ being purchased from Merck (Germany). The pharmaceutical reference standards were purchased from different suppliers as analytical grade (>98\%) solids (Appendix: Table S1). The stock solution of pharmaceuticals was prepared in methanol at a concentration of $100 \mathrm{mg} \cdot \ell^{-1}$. The ozone stock solution was prepared in a glass bottle containing purified water (Millipore-Billerica, MA) and provided with a diffuser to disperse the generated ozone from a $1.0 \mathrm{~g} \cdot \mathrm{h}^{-1} \mathrm{ozone}$ generator (O3 Technology AB, Sweden) supplied with dry oxygen gas. The bottle was immersed in an ice bath to increase ozone solubility. Detailed description of the method is found in Antoniou and Andersen (2012).

\section{WWTP effluents}

The biologically-treated wastewater effluents investigated, differing in their characteristics and representing the typical variations in alkalinity, $\mathrm{pH}$, and organic matter and ammonium content, were taken from 4 municipal WWTPs in Sweden: Öresundsverket (Effluent 1), Klagshamn (Effluent 2),
Uppsala (Effluent 3) and Käppala (Effluent 4). The effluent samples differed from one another in $\mathrm{pH}$ on the day of collection and were adjusted at the start of the experiment by use of either $\mathrm{NaOH}$ or $\mathrm{H}_{2} \mathrm{SO}_{4}$, so as to be exactly $\mathrm{pH} 6.0$ or $\mathrm{pH}$ 8.0. Table 1 shows the quality parameters of the effluents.

\section{Analysis}

COD and $\mathrm{NH}_{4}^{+}-\mathrm{N}$ were determined by use of the Hach Lange test kits LCK 114 and LCK 304 . To measure alkalinity, a $25 \mathrm{ml}$ sample was titrated with $0.05 \mathrm{M} \mathrm{HCl}$ to a $\mathrm{pH}$ of 4.5 , and then the alkalinity in mg. $\ell^{-1} \mathrm{HCO}_{3}{ }^{-}$was calculated. $\mathrm{DOC}$ was measured on the basis of wet chemical oxidation, using a Shimadzu TOC-Vwp analyser. The UV-absorbance at $254 \mathrm{~nm}$ was measured using a Varian CARY50 Bio UV-Vis spectrophotometer. The specific UV absorbance (SUVA), an indicator of the dissolved aromatic carbon that the wastewater contains, known to affect the reactivity of DOC to ozone, was determined by normalising UV absorbance at $254 \mathrm{~nm}$ to the DOC concentration (Weishaar et al., 2003). The $\mathrm{O}_{3}$ doses delivered were analysed by the colorimetric method of indigo $(\lambda=600 \mathrm{~nm})$ through preparing bottles of indigo trisulphonate solution in Milli-Q water in parallel with the treatment samples (Bader and Hoigne, 1981; Antoniou and Andersen, 2012).

For pharmaceutical analysis, $100 \mathrm{~m} \ell$ samples of the treated effluent were filtered through a $0.45 \mu \mathrm{m}$ membrane filter (Millipore) and were acidified to $\mathrm{pH} 3$ by use of sulphuric acid. After SPE extraction, LC/MS/MS analysis of the extracts was carried out, using a triple-stage quadrupole MS/MS TSQ Quantum Ultra EMR (Thermo Fisher Scientific, USA) coupled with an Accela LC pump (Thermo Fisher Scientific, USA) and a PAL HTC autosampler (CTC Analytics AG, Switzerland) having a Hypersil GOLD aQ ${ }^{\mathrm{TM}}$ column (50 mm x $2.1 \mathrm{~mm}$ ID x $5 \mu \mathrm{m}$ particles, Thermo Fisher Scientific, USA). The method of analysing pharmaceuticals was used earlier by Hörsing et al. (2011) and Hey et al. (2012). A detailed description and a full method evaluation are presented in Grabic et al. (2012). The ionisation mode, recoveries, relative standard deviations (RSD) and limit of quantification (LOQ) of the pharmaceuticals are given in the Appendix: Table S2.

\section{Experimental setup}

For the ozone consumption experiments carried out, the biologically-treated municipal wastewater was ozonated at different $\mathrm{pH}$ levels and $\mathrm{O}_{3}$ to $\mathrm{H}_{2} \mathrm{O}_{2}$ ratios. Samples were taken at different reaction times for analysis of the $\mathrm{O}_{3}$ content. For experiments involving pharmaceutical removal, the wastewater

\begin{tabular}{|c|c|c|c|c|}
\hline \multicolumn{5}{|c|}{$\begin{array}{c}\text { TABLE } 1 \\
\text { Quality parameters of the effluent wastewaters studied }\end{array}$} \\
\hline WWTPs & $\begin{array}{c}\text { Öresundsverket } \\
\text { Effluent } 1\end{array}$ & $\begin{array}{c}\text { Klagshamn } \\
\text { Effluent } 2\end{array}$ & $\begin{array}{l}\text { Uppsala } \\
\text { Effluent } 3\end{array}$ & $\begin{array}{l}\text { Käppala } \\
\text { Effluent } 4\end{array}$ \\
\hline & High pH & High pH & Low pH & Low pH \\
\hline $\operatorname{COD}\left(\mathrm{mg} \cdot \ell^{-1}\right)$ & 41.8 & 32.4 & 18.2 & 35.4 \\
\hline $\mathrm{DOC}\left(\mathrm{mg} \cdot \ell^{-1}\right)$ & 9.2 & 9.0 & 6.9 & 12.5 \\
\hline Initial alkalinity $\left(\mathrm{mg} \cdot \ell^{-1} \mathrm{HCO}_{3}^{-}\right)$ & 347.7 & 427 & 79.9 & 65.3 \\
\hline $\mathrm{NH}_{4}^{+}-\mathrm{N}\left(\mathrm{mg} \cdot \ell^{-1}\right)$ & 0.04 & 0.29 & 0.02 & 3.6 \\
\hline $\mathrm{UV}$ abs $_{254 \mathrm{~nm}}\left(\mathrm{~m}^{-1}\right)$ & 16.4 & 24.8 & 16.0 & 29.5 \\
\hline $\mathrm{pH}$ (initial) & 7.2 & 7.6 & 6.6 & 6.3 \\
\hline $\mathrm{pH}$ (adjusted) & 8.0 & 8.0 & 6.0 & 6.0 \\
\hline $\operatorname{SUVA}\left(\ell \cdot \mathrm{mg}^{-1} \cdot \mathrm{m}^{-1}\right)$ & 1.78 & 2.76 & 2.31 & 2.36 \\
\hline
\end{tabular}



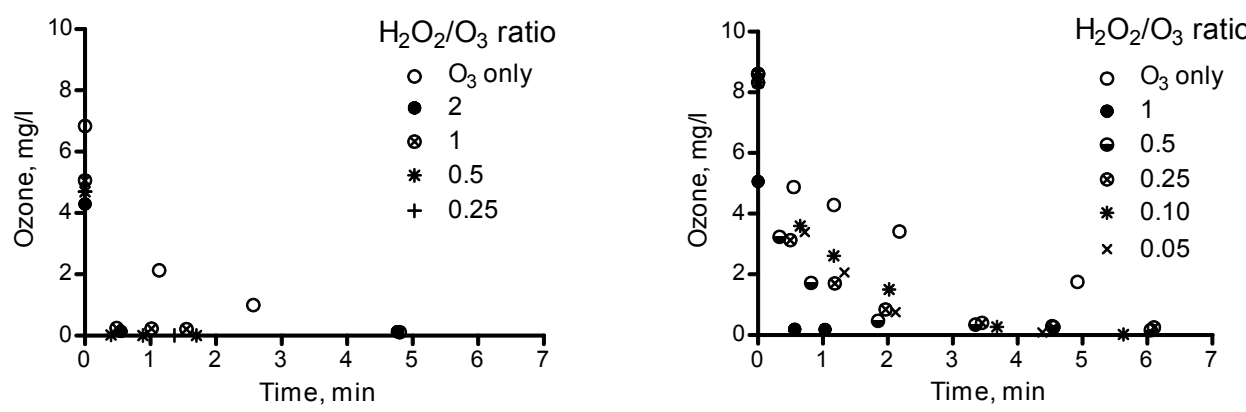

Figure 1

Ozone consumption in the WWTP effluent (Effluent 1) at pH 8 (A) and at $\mathrm{pH} 6$ (B) with different doses of $\mathrm{H}_{2} \mathrm{O}_{2}$

A

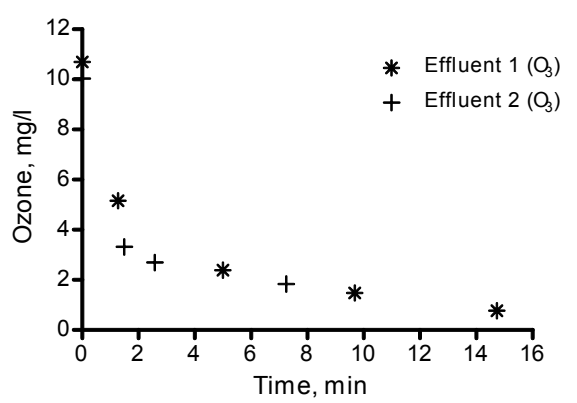

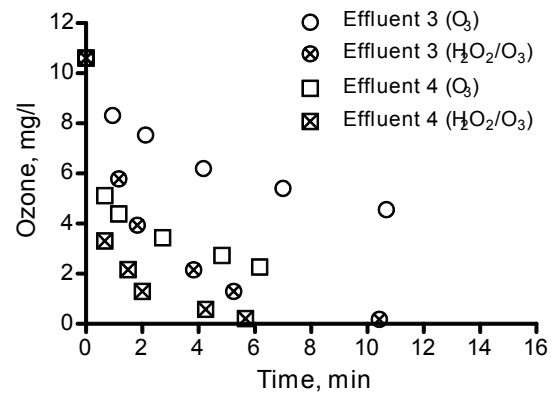

Figure 2

Ozone consumption in WWTP effluents at pH 8.0 (A, Effluents 1 and 2) without $\mathrm{H}_{2} \mathrm{O}_{2}$ and at $\mathrm{pH} 6.0$

( $\mathrm{B}$, Effluents 3 and 4) both with $\mathrm{H}_{2} \mathrm{O}_{2}$ (at $\mathrm{a} \mathrm{H}_{2} \mathrm{O}_{2} / \mathrm{O}_{3}$ ratio of 0.10 ) and without

effluents from 4 WWTPs were spiked with pharmaceuticals so as to provide a nominal concentration of $\sim 1 \mu \mathrm{g} \cdot \ell^{-1}$. The spiked effluents were then transferred into borosilicate glass bottles $\left(\right.$ Schott Duran $^{\circledR}$ ) to which different volumes of $\mathrm{O}_{3}$ stock solution were added to provide, in each case, a nominal concentration of between 1.4 and $10.7 \mathrm{mg} \cdot \ell^{-1} \mathrm{O}_{3}$ for a total sample volume of $150 \mathrm{~m} \ell$. The bottles were covered with aluminium foil and were placed in a $15^{\circ} \mathrm{C}$ water bath for $2 \mathrm{~h}$. For the $\mathrm{O}_{3}$ and $\mathrm{H}_{2} \mathrm{O}_{2}$ experiments that were conducted, the $\mathrm{H}_{2} \mathrm{O}_{2}$ was added just prior to the addition of ozone. All treatment tests conducted were run in triplicate, a relative standard deviation of up to $20 \%$ between replicates being considered for data treatment.

\section{RESULTS AND DISCUSSION}

\section{Determination of ozone concentration profiles at different $\mathrm{pH}$}

As can been seen in Fig. 1, the ozone concentration in the wastewater effluents decreased rapidly after the first minute of ozone addition. Thereafter, the rate of ozone decomposition decreased gradually and stabilised. This relatively fast ozone consumption was to be expected due to the matrix components in the wastewater consuming the oxidant. In addition, the decomposition of ozone tended to proceed faster at $\mathrm{pH} 8$ than at $\mathrm{pH} 6$, in accordance with the results of other studies, such as Hoigne and Bader (1981), using drinking water spiked with organic compounds, and Elovitz et al. (2000) which focused on surface water and groundwater. Wert et al. (2009) also demonstrated the fast consumption of ozone in real wastewaters of varying organic carbon content.
When $\mathrm{H}_{2} \mathrm{O}_{2}$ was added to the effluents at $\mathrm{H}_{2} \mathrm{O}_{2} / \mathrm{O}_{3}$ ratios ranging from 2 to 0.25 (Fig. 1), ozone was almost completely consumed during the first minute. As could be expected, the effluent of high $\mathrm{pH}$ ( $\mathrm{pH}$ 8) exhibited the fastest ozone decomposition rate $(<1 \mathrm{~min})$. An additional experiment was also carried out at $\mathrm{pH} 6.0$, involving the use of lower doses of $\mathrm{H}_{2} \mathrm{O}_{2}$, resulting in significantly lower $\mathrm{H}_{2} \mathrm{O}_{2} / \mathrm{O}_{3}$ ratios of $0.05-0.10$. As can be seen (Fig. 1), the differences in ozone removal rate between the samples are most obvious in the first minute or so of treatment, where the decomposition of ozone increased with an increase in the $\mathrm{H}_{2} \mathrm{O}_{2} / \mathrm{O}_{3}$ ratio for around $2 \mathrm{~min}$, after which nearly all the ozone has been consumed.

\section{$O_{3}$ concentration profiles in the WWTP effluents tested}

On the basis of these findings, it is obvious that the addition of relatively small amounts of $\mathrm{H}_{2} \mathrm{O}_{2}$ is able to change the ozone concentration profile appreciably. To investigate this further, a set of experiments was carried out using 4 different effluent wastewaters (Table 1), two with relatively high $\mathrm{pH}$ and two with relatively low $\mathrm{pH}$. The effluents, after $\mathrm{pH}$ adjustments to 8.0 and 6.0 , respectively, were treated with ozone and the decomposition was followed (Fig. 2). In the high-pH effluents (Fig. 2A), about half of the ozone was already consumed during the first minute, especially in the case of Effluent 2. The differences observed can be attributed to the higher SUVA content in Effluent 2 than in Effluent 1 (Table 1). The relatively high content of aromatic compounds, indicated by the relatively high SUVA level, could explain the increased ozone consumption in the early stages of treatment, due to fast reactivity of aromatic compounds, as also observed by Westerhoff et al. (1999). At pH 


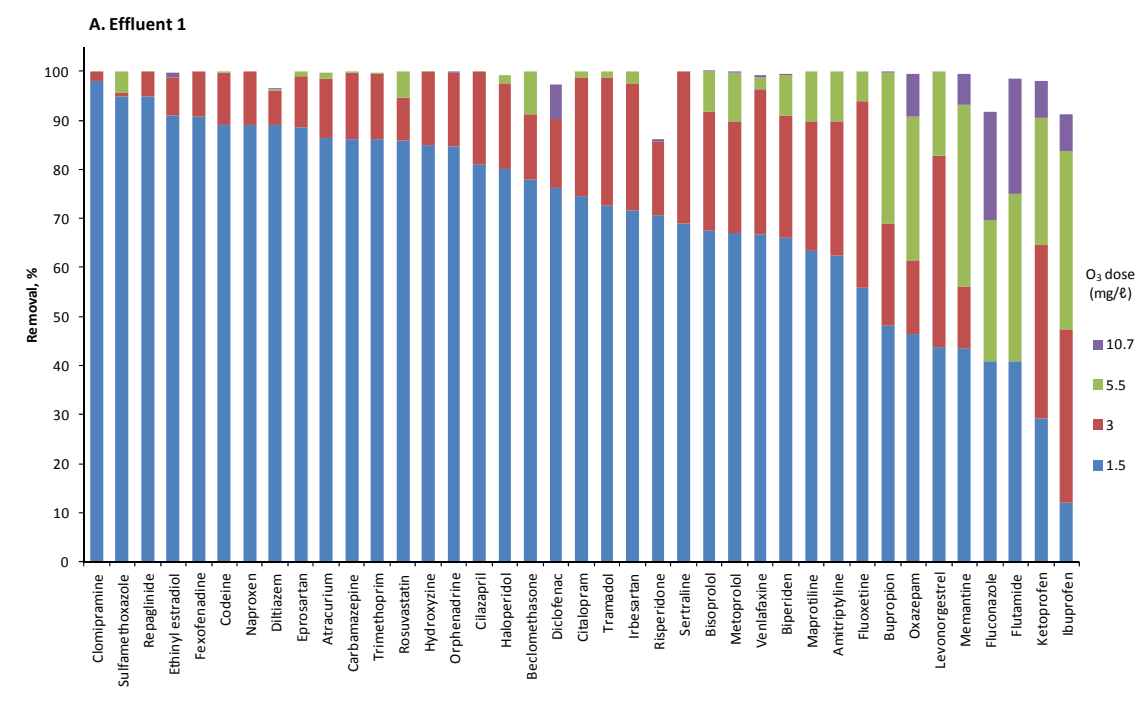

Figure 3
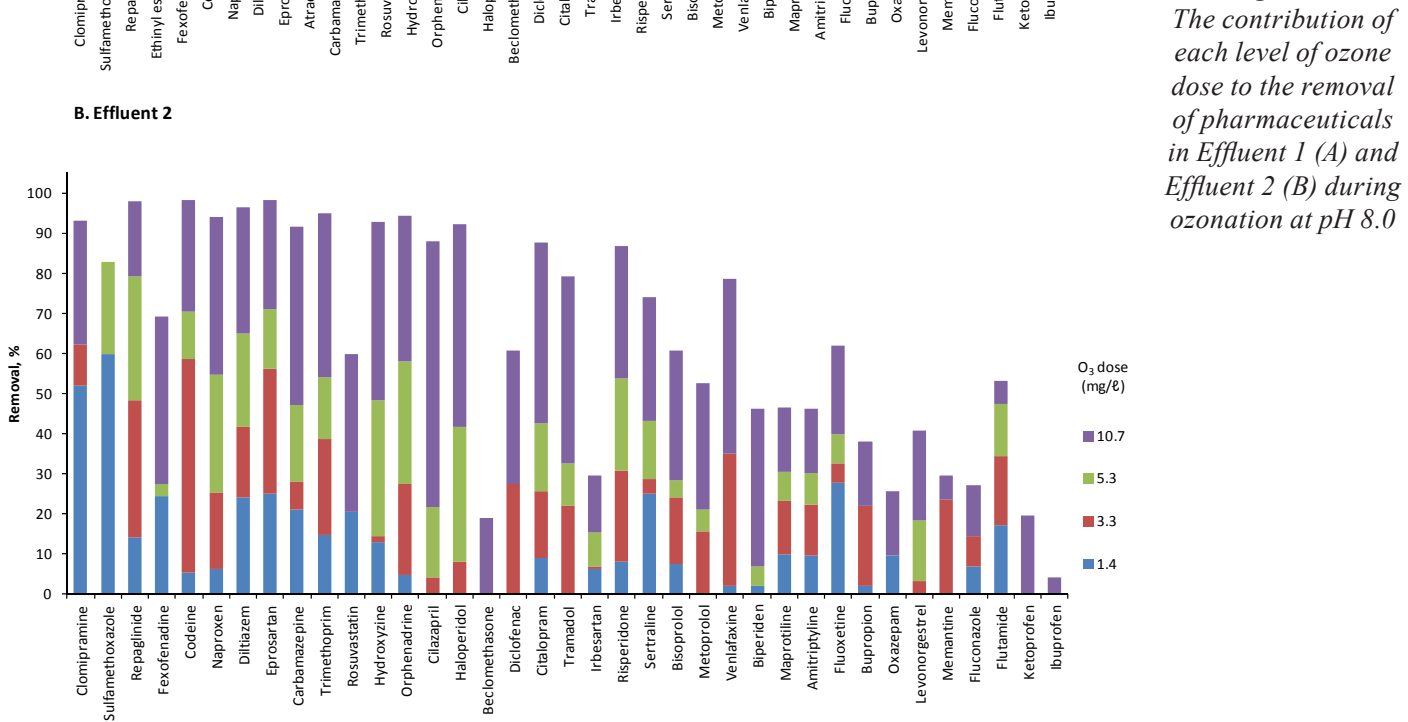

ozonation at $\mathrm{pH} 8.0$

6.0, in contrast, Effluent 3 appears to have a much lower ozone demand than Effluent 4 (Fig. 2B), this probably being due to the lower organic content of Effluent 3, which is only about half that of Effluent 4. Similar to what can be seen above (Fig. 1), the addition of $\mathrm{H}_{2} \mathrm{O}_{2}$ to the effluent led to an increased decomposition of ozone, measured as a decline in ozone concentration.

These findings show that it is important, when employing ozonation, to investigate the initial ozone demand of the wastewater due to matrix effects. The present findings also show that at low $\mathrm{pH}$ the combination of ozone and $\mathrm{H}_{2} \mathrm{O}_{2}$ reduces the reaction time, indicating that it is possible to reduce the size of the reaction tank employed for treatment.

\section{Removal of pharmaceuticals by $\mathrm{O}_{3}$ and $\mathrm{H}_{2} \mathrm{O}_{2}$}

In the ozonation of $\mathrm{pH} 8.0$ effluents, a significant reduction in the different pharmaceuticals was found, especially in the case of Effluent 1 (Fig. 3A), even at relatively low doses of ozone. At the lowest dose $\left(1.5 \mathrm{mg} \cdot \ell^{-1} \mathrm{O}_{3}\right), 9$ of the 40 pharmaceuticals (clomipramine, sulfamethoxazole, repaglinide, ethinyl estradiol, fexofenadine, codeine, naproxen, diltiazem and eprosartan) already showed removal rates of $90-100 \%$; only 8 of the pharmaceuticals (bupropion, oxazepam, levonorgestrel, memantine, fluconazole, flutamide, ketoprofen and ibuprofen) exhibited $<50 \%$ removal. As the ozone dose was increased, most of the pharmaceuticals, including the less reactive ones, were degraded.
On the other hand, in Effluent 2 (Fig. 3B), the pharmaceuticals were poorly removed, even when the $\mathrm{O}_{3}$ dose was increased. This can be attributed to the high SUVA level (2.76 as compared with 1.78) of this effluent. The high ozone reactivity of the aromatic components of the DOC may have contributed to the decrease in pharmaceutical removal from the effluent. Also, as can be observed in Fig. 3, some of the pharmaceuticals in Effluent 1 exhibited a high level of removal in response to the lowest ozone dose but did not follow the same pattern of removal in Effluent 2. For example, both clomipramine and repaglinide showed a high degree of removal at the lowest ozone dose, yet when treated with the same $\mathrm{O}_{3}$ dose in Effluent 2 it was only clomipramine for which the degree of removal was significant $(\sim 50 \%)$. This shows clearly that both the level of removal and the reactivity of pharmaceuticals can vary depending upon the composition of the wastewater matrix.

The efficiency of ozone in removing pharmaceuticals from pH 6.0 effluents (Fig. 4A) showed that ozone alone could remove $>90 \%$ of half of the pharmaceuticals present in Effluent 3 at the lowest ozone dose $\left(1.8 \mathrm{mg} \cdot \ell^{-1}\right)$. When the dose was increased to $4.4 \mathrm{mg} \cdot \ell^{-1}$, all pharmaceuticals except fluconazole were degraded by over $90 \%$. A still further increase in the ozone dose resulted in over $99 \%$ removal of all pharmaceuticals, except fluconazole (93\%) and ibuprofen (96\%). In contrast, the ozonation of Effluent 4 resulted in $>90 \%$ degradation of the pharmaceuticals when rather high doses of ozone $\left(>5 \mathrm{mg} \cdot \ell^{-1}\right)$ were employed (Fig. 4B). In comparison to the $\mathrm{pH} 8.0$ effluent 


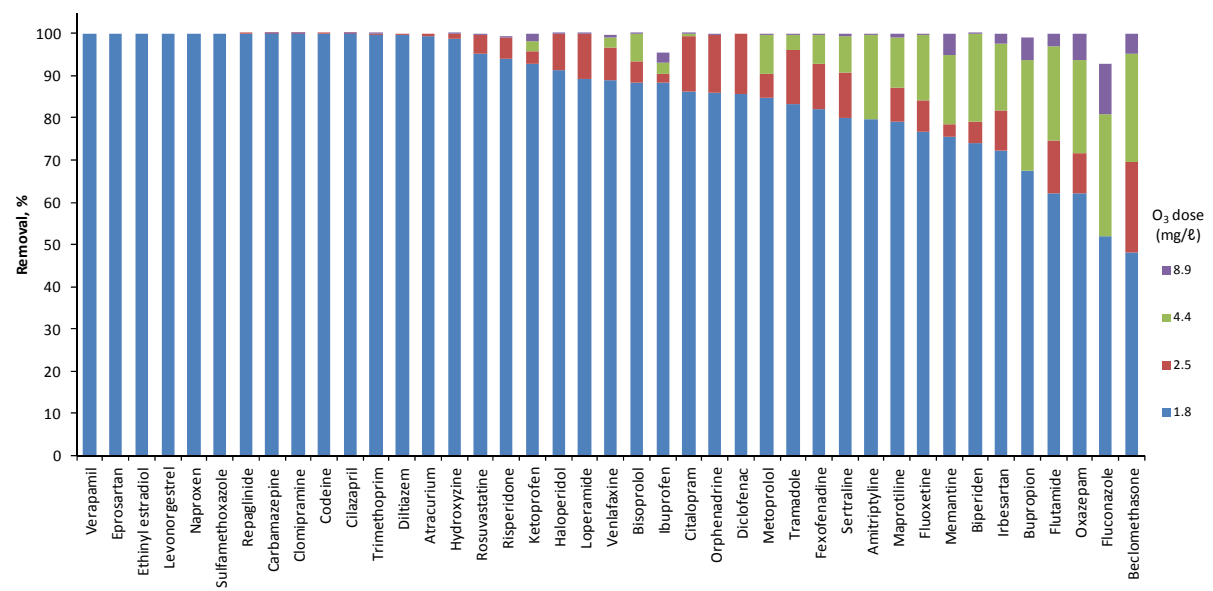

B. Effluent 4

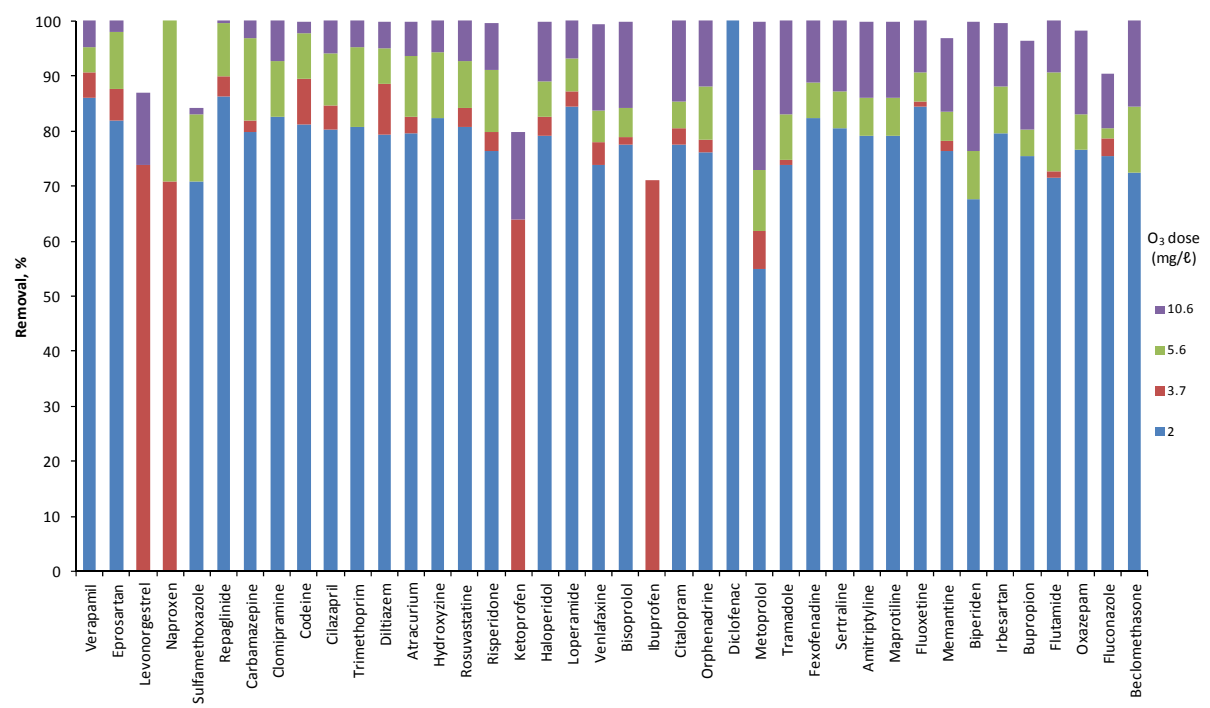

\section{Figure 4}

The contribution of each level of ozone dose to the removal of pharmaceuticals in Effluent 3 (A) and Effluent 4 (B) during ozonation at $\mathrm{pH} 6.0$

(Effluent 1), the observed high removal of pharmaceuticals in the pH 6.0 effluent (Effluent 3 ) is likely due to the very low organic content of this effluent (Table 1), which resulted in more ozone being available (Fig. 2B) to react with the pharmaceuticals.

Figure 5 illustrates the contribution of $\mathrm{H}_{2} \mathrm{O}_{2}$ addition to the removal of those pharmaceuticals that have been shown to have the lowest reactivity towards ozone. For fluconazole (Effluent 3), as can be seen, there was only a slight increase in removal after the addition of $\mathrm{H}_{2} \mathrm{O}_{2}$, whereas for ibuprofen no improvement in its removal occurred. Thus, the addition of $\mathrm{H}_{2} \mathrm{O}_{2}$ (at an $\mathrm{H}_{2} \mathrm{O}_{2}$ / $\mathrm{O}_{3}$ ratio of $0.08-0.13$ ) to an initial ozone dose of $10 \mathrm{mg} \cdot \ell^{-1}$

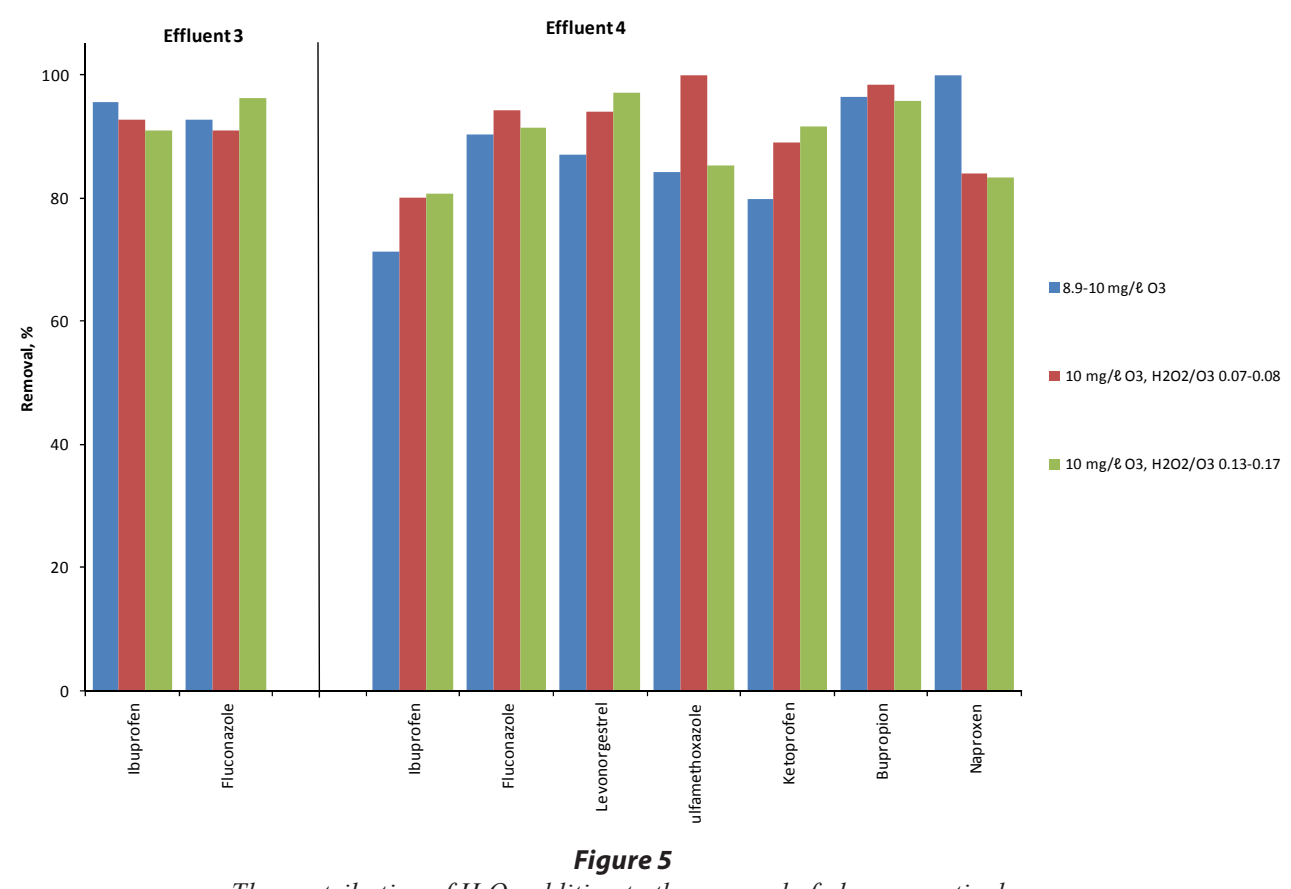

The contribution of $\mathrm{H}_{2} \mathrm{O}_{2}$ addition to the removal of pharmaceuticals less reactive to ozone in Effluent 3 and Effluent 4 


\begin{tabular}{|c|c|c|c|c|c|c|c|c|c|}
\hline \multicolumn{10}{|c|}{$\begin{array}{l}\text { TABLE } 2 \\
\text { Pharmaceuticals for which at least } 90 \% \text { removal }(\checkmark) \text { occurs in each of the effluents when treated } \\
\text { with } \sim 5 \mathrm{mg} \cdot \ell^{-1} \mathrm{O}_{3} \text {. (NA = compound not quantified) }\end{array}$} \\
\hline \multirow[t]{2}{*}{ Pharmaceuticals } & \multicolumn{2}{|c|}{ (High pH) } & \multicolumn{2}{|c|}{ (Low pH) } & \multirow[b]{2}{*}{ Pharmaceuticals } & \multicolumn{2}{|c|}{ (High pH) } & \multicolumn{2}{|c|}{ (Low pH) } \\
\hline & Eff 1 & Eff 2 & Eff 3 & Eff 4 & & Eff 1 & Eff 2 & Eff 3 & Eff 4 \\
\hline Amitriptyline & $\checkmark$ & - & $\checkmark$ & $\checkmark$ & Hydroxyzine & $\checkmark$ & - & $\checkmark$ & $\checkmark$ \\
\hline Atracurium & $\checkmark$ & NA & $\checkmark$ & $\checkmark$ & Ibuprofen & - & - & $\checkmark$ & \\
\hline Beclomethasone & - & - & $\checkmark$ & - & Irbesartan & $\checkmark$ & - & $\checkmark$ & $\checkmark$ \\
\hline Biperiden & - & - & $\checkmark$ & - & Ketoprofen & - & - & $\checkmark$ & - \\
\hline Bisoprolol & - & - & $\checkmark$ & - & Levonorgestrel & - & - & $\checkmark$ & - \\
\hline Bupropion & - & - & $\checkmark$ & - & Loperamide & NA & $\checkmark$ & $\checkmark$ & $\checkmark$ \\
\hline Carbamazepine & $\checkmark$ & - & $\checkmark$ & $\checkmark$ & Maprotiline & $\checkmark$ & - & $\checkmark$ & $\checkmark$ \\
\hline Cilazapril & $\checkmark$ & - & $\checkmark$ & $\checkmark$ & Memantine & - & - & $\checkmark$ & - \\
\hline Citalopram & $\checkmark$ & - & $\checkmark$ & $\checkmark$ & Metoprolol & - & - & $\checkmark$ & - \\
\hline Clomipramine & $\checkmark$ & - & $\checkmark$ & $\checkmark$ & Naproxen & $\checkmark$ & - & $\checkmark$ & $\checkmark$ \\
\hline Codeine & $\checkmark$ & - & $\checkmark$ & $\checkmark$ & Orphenadrine & $\checkmark$ & - & $\checkmark$ & $\checkmark$ \\
\hline Diclofenac & $\checkmark$ & - & $\checkmark$ & $\checkmark$ & Oxazepam & - & - & $\checkmark$ & - \\
\hline Diltiazem & $\checkmark$ & - & $\checkmark$ & $\checkmark$ & Repaglinide & $\checkmark$ & - & $\checkmark$ & $\checkmark$ \\
\hline Eprosartan & $\checkmark$ & - & $\checkmark$ & $\checkmark$ & Risperidone & $\checkmark$ & - & $\checkmark$ & $\checkmark$ \\
\hline Ethinyl estradiol & $\checkmark$ & NA & $\checkmark$ & NA & Rosuvastatin & $\checkmark$ & - & $\checkmark$ & $\checkmark$ \\
\hline Fexofenadine & $\checkmark$ & - & $\checkmark$ & $\checkmark$ & Sertraline & $\checkmark$ & - & $\checkmark$ & $\checkmark$ \\
\hline Fluconazole & - & - & - & - & Sulfamethoxazole & - & - & $\checkmark$ & - \\
\hline Fluoxetine & $\checkmark$ & - & $\checkmark$ & $\checkmark$ & Tramadol & - & - & $\checkmark$ & - \\
\hline Flutamide & $\checkmark$ & - & $\checkmark$ & $\checkmark$ & Trimethoprim & $\checkmark$ & - & $\checkmark$ & $\checkmark$ \\
\hline Haloperidol & $\checkmark$ & - & $\checkmark$ & $\checkmark$ & Venlafaxine & $\checkmark$ & - & $\checkmark$ & - \\
\hline
\end{tabular}

could not be expected to have any appreciable impact on the removal of pharmaceuticals in this effluent. On the other hand, for Effluent 4, the addition of $\mathrm{H}_{2} \mathrm{O}_{2}$ was found to enhance the removal of ibuprofen, fluconazole, levonorgestrel, sulfamethoxazole and ketoprofen by only $4-16 \%$ and of naproxenl by $\sim 15 \%$.

The overall findings of this study show that reaction time can be reduced when ozone is combined with small amounts of $\mathrm{H}_{2} \mathrm{O}_{2}$, which will be advantageous when practical implementation of the technology takes place. As for most pharmaceuticals, this addition has no impact on removal efficiency, i.e., neither increasing nor decreasing its removal.

The majority of pharmaceuticals included in this study contained acidic and/or basic groups, having different and $\mathrm{pH}$-dependent charges (positive, neutral or negative) and, as a result, may also differ in their tertiary chemical structure, as a function of $\mathrm{pH}$. The pharmaceuticals that are acidic can be protolysed at $\mathrm{pH} 6$, with no further changes occurring then when the $\mathrm{pH}$ is increased to 8 . In contrast, those pharmaceuticals that have basic group(s) and low $p K_{b}$ values go from being unprotolysed at $\mathrm{pH} 6$ to being protolysed at $\mathrm{pH} 8$, the charge thus changing from positive to neutral, which can result in a change in the tertiary structure. Those pharmaceuticals having both acidic and basic groups may also undergo changes in the charge and in their tertiary structure. This can be expected to have an impact on the oxidation rate. It is not possible, however, on the basis of the experiments carried out here, to draw any final conclusions regarding this.

Table 2 provides an overview of the findings regarding removal efficiencies for the pharmaceuticals that were investigated. It can readily be seen that an ozone dose of around $5 \mathrm{mg} \cdot \ell^{-1}$ is sufficient to remove over half of the target pharmaceuticals, except in the case of Effluent 2, in which a much higher ozone dose may be required for removing a large fraction of the pharmaceuticals, this most likely being due to the higher SUVA level of Effluent 2. At the same time, it appears that, in the case of wastewaters such as Effluent 3 that are low in $\mathrm{pH}$ and organic content, a reasonable dose of ozone to remove over $90 \%$ of the pharmaceuticals is around $5 \mathrm{mg} \cdot \ell^{-1}$.

The oxidation of pharmaceuticals may lead to the production of by- and transformation products. Since these can be toxic to varying degrees as compared with the mother compound, toxicity evaluation of a given technology should be performed before it is considered for implementation.

\section{CONCLUSIONS}

The following conclusions can be drawn on the basis of the results of the study:

- Ozonation can be employed as an additional treatment step to enable trace pharmaceuticals to be removed effectively from wastewater effluents.

- The amount of ozone required for the removal of pharmaceuticals is dependent upon the chemical composition of the wastewater and upon the target compounds, with the content of organic matter in general and its aromaticity being of considerable importance.

- Ozone decomposition can be stimulated by adding hydrogen peroxide at low $\mathrm{pH}$. The addition of hydrogen peroxide has only a limited impact on the quantitative removal of pharmaceuticals. However, it reduces the treatment time and, accordingly, the reaction volume needed, which will be advantageous in practice. 


\section{ACKNOWLEDGEMENTS}

The authors would like to thank the Swedish Foundation for Strategic Environmental Research through its MistraPharma programme for the financial support of this study. We also thank the staff and the process engineers of the WWTPs of Öresundsverket, Klagshamn, Uppsala and Käppala for the wastewater samples they provided.

\section{REFERENCES}

ANTONIOU MG and ANDERSEN HR (2012) Evaluation of pretreatments for inhibiting bromate formation during ozonation. Environ. Technol. 33 (15) 1747-1753.

BADER H and HOIGNE J (1981) Determination of ozone in water by the indigo method. Water Res. 15 (4) 449-456.

BAHR C, SCHUMACHER J, ERNST M, LUCK F, HEINZMANN B and JEKEL M (2007) SUVA as control parameter for the effective ozonation of organic pollutants in secondary effluent. Water Sci. Technol. 55 (12) 267-274.

BALCIOGLU IA and ÖTKER M (2003) Treatment of pharmaceutical wastewater containing antibiotics by $\mathrm{O}_{3}$ and $\mathrm{O}_{3} / \mathrm{H}_{2} \mathrm{O}_{2}$ processes. Chemosphere 50 85-95.

BATT AL, SNOW DD and AGA DS (2006) Occurrence of sulfonamide antimicrobials in private water wells in Washington County, Idaho, USA. Chemosphere 64 1963-1971.

BENNER J and TERNES TA (2009) Ozonation of metoprolol: Elucidation of oxidation pathways and major oxidation products. Environ. Sci. Technol. 43 (14) 5472-5480.

BUFFLE MO, SCHUMACHER J, SALHI E, JEKEL M and VON GUNTEN U (2006a) Measurement of the initial phase of ozone decomposition in water and wastewater by means of a continuous quench-flow system: Application to disinfection and pharmaceutical oxidation. Water Res. 40 (9 1884-1894.

BUFFLE MO, SCHUMACHER J, MEYLAN S, JEKEL M and VON GUNTEN U (2006b) Ozonation and advanced oxidation of wastewater: Effect of $\mathrm{O}_{3}$ dose, $\mathrm{pH}, \mathrm{DOM}$ and $\mathrm{HO}^{*}$-scavengers on ozone decomposition and HO^ generation. Ozone: Sci. Eng. 28 (4) 247-259.

ELOVITZ M, VON GUNTEN U and KAISER HP (2000) Hydroxyl radicals/ozone ratios during ozonation processes. II. The effect of temperature, $\mathrm{pH}$, alkalinity, and DOM properties. Ozone: Sci. Eng. 22 123-150.

FALÅS P, ANDERSEN HR, LEDIN A and LA COUR JANSEN J (2012) Occurrence and reduction of pharmaceuticals in the water phase at Swedish wastewater treatment plants. Water Sci. Technol. 66 (4) 783-791.

FENT K, WESTON AA and CAMINADA D (2006) Ecotoxicology of human pharmaceuticals. Aquat. Toxicol. 76 122-159.

GRABIC R, FICK J, LINDBERG RH, FEDOROVA G and TYSKLIND M (2012) Multi-residue method for trace level determination of pharmaceuticals in environmental samples using liquid chromatography coupled to triple quadrupole mass spectrometry. Talanta 100 183-195.

HANSEN KMS, ANDERSEN HR and LEDIN A (2010) Ozonation of estrogenic chemicals in biologically treated sewage. Water Sci. Technol. 62 649-657.

HANSEN KMS and ANDERSEN HR (2012) Energy effectiveness of direct UV and UV/H2O2 treatment of estrogenic chemicals in biologically treated sewage. Int. J. Photoenergy 2012 doi: $10.1155 / 2012 / 27030$

HEY G, GRABIC R, LEDIN A, LA COUR JANSEN J and ANDERSEN HR (2012) Oxidation of pharmaceuticals by chlorine dioxide in biologically treated wastewater. Chem. Eng. J. 185-186 236-242.

HOIGNE H and BADER H (1983) Rate constants of reactions of ozone with organic and inorganic compounds in water. II. Dissociating organic compounds. Water Res. 17 (2) 185-194.
HOLLENDER J, ZIMMERMANN SG, KOEPKE S, KRAUSS M, MCARDELL CS, ORT C, SINGER H, VON GUNTEN U and SIEGRIST H (2009) Elimination of organic micropollutants in a municipal wastewater treatment plant upgraded with a full-scale post-ozonation followed by sand filtration. Environ. Sci. Technol. 43 (20) 7862-7869.

HUBER MM, CANONICA S, PARK GY and VON GUNTEN U (2003) Oxidation of pharmaceuticals during ozonation and advanced oxidation processes. Environ. Sci. Technol. 37 (5) 1016-1024.

HUBER MM, GÖBEL A, JOSS A, HERMANN N, LÖFFLER D, McARDELL CS, RIED A, SIEGRIST H, TERNES TA and VON GUNTEN U (2005) Oxidation of pharmaceuticals during ozonation of municipal wastewater effluents: A pilot study. Environ. Sci. Technol. 39 (11) 4290-4299.

HÖRSING M, LEDIN A, GRABIC R, FICK J, TYSKLIND M, LA COUR JANSEN J and ANDERSEN HR (2011) Determination of sorption of seventy-five pharmaceuticals in sewage sludge. Water Res. 45 4470-4482.

KOLPIN DW, FURLONG ET, MEYER MT, THURMAN EM, ZAUGG SD, BARBER LB and BUXTON HT (2002) Pharmaceuticals, hormones, and other organic wastewater contaminants in U.S. streams, 1999-2000: a national reconnaissance. Environ. Sci. Technol. 36 1202-1211.

LEE Y and VON GUNTEN U (2010) Oxidative transformation of micropollutants during municipal wastewater treatment: Comparison of kinetic aspects of selective (chlorine, chlorine dioxide, ferrateVI, and ozone) and non-selective oxidants (hydroxyl radical). Water Res. 44 (2) 555-566.

NÖTHE T, FAHLENKAMP H and VON SONNTAG C (2009) Ozonation of wastewater: Rate of ozone consumption and hydroxyl radical yield. Environ. Sci. Technol. 43 5990-5995.

ROSENFELDT EJ, LINDEN KG, CANONICA S and VON GUNTEN $\mathrm{U}$ (2006) Comparison of the efficiency of ${ }^{\circ} \mathrm{OH}$ radical formation during ozonation and the advanced oxidation processes $\mathrm{O}_{3} / \mathrm{H}_{2} \mathrm{O}_{2}$ and $\mathrm{UV} / \mathrm{H}_{2} \mathrm{O}_{2}$. Water Res. 40 3695-3704.

SNYDER SA (2008) Occurrence, treatment, and toxicological relevance of EDCs and pharmaceuticals in water. Ozone: Sci. Eng. 30 65-69.

TERNES TA (1998) Occurrence of drugs in German sewage treatment plants and rivers. Water Res. 32 3245-3260.

TERNES TA, STÜBER J, HERRMANN N, MCDOWELL D, RIED A, KAMPMANN M and TEISER B (2003) Ozonation: a tool for removal of pharmaceuticals, contrast media and musk fragrances from wastewater? Water Res. 37 (8) 1976-1982.

VERLICCHI P, AL AUKIDY M and ZAMBELLO E (2012) Occurrence of pharmaceutical compounds in urban wastewater: Removal, mass load and environmental risk after a secondary treatment A review. Sci. Total Environ. 429 123-155.

VON GUNTEN U (2003) Ozonation of drinking water: Part I. Oxidation kinetics and product formation. Water Res. 37 1443-1467.

WEISHAAR JL, AIKEN GR, BERGAMASCHI B, FRAM MS, FUGII $R$ and MOPPER K (2003) Evaluation of specific ultraviolet absorbance as an indicator of the chemical composition and reactivity of dissolved organic carbon. Environ. Sci. Technol. 37 4702-4708.

WERT EC, ROSARIO-ORTIZ FL and SNYDER SA (2009) Effect of ozone exposure on the oxidation of trace organic contaminants in wastewater. Water Res. 43 (4) 1005-1014.

WESTERHOFF P, AIKEN G, AMY G and DEBROUX J (1999) Relationships between the structure of natural organic matter and its reactivity towards molecular ozone and hydroxyl radicals. Water Res. 33 (10) 2265-2276.

ZIMMERMANN SG, WITTENWILER M, HOLLENDER J, KRAUSS M, ORT C, SIEGRIST H and VON GUNTEN U (2011) Kinetic assessment and modeling of an ozonation step for full-scale municipal wastewater treatment: Micropollutant oxidation, by-product formation and disinfection. Water Res. 45 (2) 605-617.

ZWIENER C and FRIMMEL FH (2000) Oxidative treatment of pharmaceuticals in water. Water Res. 34 (6) 1881-1885. 


\section{Appendix}

Supplementary information: Removal of pharmaceuticals in WWTP effluents by ozone and hydrogen peroxide

TABLE S1

List of suppliers for pharmaceuticals and the corresponding internal standards used for quantification

\begin{tabular}{|c|c|c|c|}
\hline Pharmaceuticals & Supplier & Internal standards & Supplier \\
\hline Amitryptiline & Sigma-Aldrich (Steinheim, Germany) & ${ }^{2} \mathrm{H}_{6}-$ Amitriptyline & Cambridge Isotope Laboratories (Andover, MA, USA) \\
\hline Atracurium & Sigma-Aldrich (Steinheim, Germany) & ${ }^{13} \mathrm{C}^{2} \mathrm{H}_{3}$ - Tramadol & Cambridge Isotope Laboratories (Andover, MA, USA) \\
\hline Beclomethasone & Sigma-Aldrich (Steinheim, Germany) & ${ }^{2} \mathrm{H}_{5}$ - Oxazepam & Sigma-Aldrich (Steinheim, Germany) \\
\hline Biperiden & Sigma-Aldrich (Steinheim, Germany) & ${ }^{2} \mathrm{H}_{6}$ - Amitriptyline & Cambridge Isotope Laboratories (Andover, MA, USA) \\
\hline Bisoprolol & Sigma-Aldrich (Steinheim, Germany) & ${ }^{13} \mathrm{C}^{2} \mathrm{H}_{3}$ - Tramadol & Cambridge Isotope Laboratories (Andover, MA, USA) \\
\hline Bupropion & Sigma-Aldrich (Steinheim, Germany) & ${ }^{13} \mathrm{C}^{2} \mathrm{H}_{3}$ - Tramadol & Cambridge Isotope Laboratories (Andover, MA, USA) \\
\hline Carbamazepine & Sigma-Aldrich (Steinheim, Germany) & ${ }^{2} \mathrm{H}_{10}$ - Carbamazepine & Cambridge Isotope Laboratories (Andover, MA, USA) \\
\hline Cilazapril & LGC Standards (Middlesex, UK) & ${ }^{13} \mathrm{C}^{2} \mathrm{H}_{3}$ - Tramadol & Cambridge Isotope Laboratories (Andover, MA, USA) \\
\hline Citalopram & Sigma-Aldrich (Steinheim, Germany) & ${ }^{13} \mathrm{C}^{2} \mathrm{H}_{3}$ - Tramadol & Cambridge Isotope Laboratories (Andover, MA, USA) \\
\hline Clomipramine & Sigma-Aldrich (Steinheim, Germany) & ${ }^{2} \mathrm{H}_{6}$ - Amitriptyline & Cambridge Isotope Laboratories (Andover, MA, USA) \\
\hline Codeine & Sigma-Aldrich (Steinheim, Germany) & ${ }^{13} \mathrm{C}^{2} \mathrm{H}_{3}$ - Tramadol & Cambridge Isotope Laboratories (Andover, MA, USA) \\
\hline Diclofenac & Sigma-Aldrich (Steinheim, Germany) & ${ }^{13} \mathrm{C}^{2} \mathrm{H}_{3}$ - Tramadol & Cambridge Isotope Laboratories (Andover, MA, USA) \\
\hline Diltiazem & Sigma-Aldrich (Steinheim, Germany) & ${ }^{13} \mathrm{C}^{2} \mathrm{H}_{3}$ - Tramadol & Cambridge Isotope Laboratories (Andover, MA, USA) \\
\hline Eprosartan & CHEMOS GmbH (Regenstauf, Germany) & ${ }^{2} \mathrm{H}_{10}$ - Carbamazepine & Cambridge Isotope Laboratories (Andover, MA, USA) \\
\hline Ethinyl estradiol & Sigma-Aldrich (Steinheim, Germany) & ${ }^{13} \mathrm{C}_{2}$. Ethinyl estradiol & Cambridge Isotope Laboratories (Andover, MA, USA) \\
\hline Fexofenadine & Sigma-Aldrich (Steinheim, Germany) & ${ }^{2} \mathrm{H}_{6}$ - Amitriptyline & Cambridge Isotope Laboratories (Andover, MA, USA) \\
\hline Fluconazole & Sigma-Aldrich (Steinheim, Germany) & ${ }^{13} \mathrm{C}_{3}$ - Trimethoprim & Cambridge Isotope Laboratories (Andover, MA, USA) \\
\hline Fluoxetine & Sigma-Aldrich (Steinheim, Germany) & ${ }^{2} \mathrm{H}_{5}$ - Fluoxetine & Cambridge Isotope Laboratories (Andover, MA, USA) \\
\hline Flutamide & Sigma-Aldrich (Steinheim, Germany) & ${ }^{2} \mathrm{H}_{6}$ - Amitriptyline & Cambridge Isotope Laboratories (Andover, MA, USA) \\
\hline Haloperidol & Sigma-Aldrich (Steinheim, Germany) & ${ }^{13} \mathrm{C}^{2} \mathrm{H}_{3}$ - Tramadol & Cambridge Isotope Laboratories (Andover, MA, USA) \\
\hline Hydroxyzine & Sigma-Aldrich (Steinheim, Germany) & ${ }^{2} \mathrm{H}_{6}$ - Amitriptyline & Cambridge Isotope Laboratories (Andover, MA, USA) \\
\hline Ibuprofen & Sigma-Aldrich (Steinheim, Germany) & ${ }^{13} \mathrm{C}_{3}$ - Ibuprofen & Cambridge Isotope Laboratories (Andover, MA, USA) \\
\hline Irbesartan & CHEMOS GmbH (Regenstauf, Germany) & ${ }^{2} \mathrm{H}_{6}$ - Amitriptyline & Cambridge Isotope Laboratories (Andover, MA, USA) \\
\hline Ketoprofen & Sigma-Aldrich (Steinheim, Germany) & ${ }^{13} \mathrm{C}_{3}{ }^{2} \mathrm{H}_{3}$ - Naproxen & Cambridge Isotope Laboratories (Andover, MA, USA) \\
\hline Levonorgestrel & LGC Standards (Middlesex, UK) & ${ }^{13} \mathrm{C}_{2}-$ Ethinyl estradiol & Cambridge Isotope Laboratories (Andover, MA, USA) \\
\hline Loperamide & Sigma-Aldrich (Steinheim, Germany) & ${ }^{2} \mathrm{H}_{6}$ - Amitriptyline & Cambridge Isotope Laboratories (Andover, MA, USA) \\
\hline Maprotiline & Sigma-Aldrich (Steinheim, Germany) & ${ }^{2} \mathrm{H}_{6}$ - Amitriptyline & Cambridge Isotope Laboratories (Andover, MA, USA) \\
\hline Memantine & Sigma-Aldrich (Steinheim, Germany) & ${ }^{13} \mathrm{C}^{2} \mathrm{H}_{3}$ - Tramadol & Cambridge Isotope Laboratories (Andover, MA, USA) \\
\hline Metoprolol & Sigma-Aldrich (Steinheim, Germany) & ${ }^{13} \mathrm{C}^{2} \mathrm{H}_{3}$ - Tramadol & Cambridge Isotope Laboratories (Andover, MA, USA) \\
\hline Naproxen & Sigma-Aldrich (Steinheim, Germany) & ${ }^{13} \mathrm{C}_{3}{ }^{2} \mathrm{H}_{3}$ - Naproxen & Cambridge Isotope Laboratories (Andover, MA, USA) \\
\hline Orphenadrine & LGC Standards (Middlesex, UK) & ${ }^{2} \mathrm{H}_{6}$ - Amitriptyline & Cambridge Isotope Laboratories (Andover, MA, USA) \\
\hline Oxazepam & Sigma-Aldrich (Steinheim, Germany) & ${ }^{2} \mathrm{H}_{5}-$ Oxazepam & Sigma-Aldrich (Steinheim, Germany) \\
\hline Repaglinide & Sigma-Aldrich (Steinheim, Germany) & ${ }^{2} \mathrm{H}_{6}$ - Amitriptyline & Cambridge Isotope Laboratories (Andover, MA, USA) \\
\hline Risperidone & LGC Standards (Middlesex, UK) & ${ }^{2} \mathrm{H}_{4}$ - Risperidone & Sigma-Aldrich (Steinheim, Germany) \\
\hline Rosuvastatin & CHEMOS GmbH (Regenstauf, Germany) & ${ }^{13} \mathrm{C}^{2} \mathrm{H}_{3}$ - Tramadol & Cambridge Isotope Laboratories (Andover, MA, USA) \\
\hline Sertraline & Sigma-Aldrich (Steinheim, Germany) & ${ }^{2} \mathrm{H}_{6}$ - Amitriptyline & Cambridge Isotope Laboratories (Andover, MA, USA) \\
\hline Sulfamethoxazole & Sigma-Aldrich (Steinheim, Germany) & ${ }^{13} \mathrm{C}_{6}$ - Sulfamethoxazole & Cambridge Isotope Laboratories (Andover, MA, USA) \\
\hline Tramadol & Sigma-Aldrich (Steinheim, Germany) & ${ }^{13} \mathrm{C}^{2} \mathrm{H}_{3}$ - Tramadol & Cambridge Isotope Laboratories (Andover, MA, USA) \\
\hline Trimethoprim & Sigma-Aldrich (Steinheim, Germany) & ${ }^{13} \mathrm{C}_{3}$ - Trimethoprim & Cambridge Isotope Laboratories (Andover, MA, USA) \\
\hline Venlafaxine & Sigma-Aldrich (Steinheim, Germany) & ${ }^{13} \mathrm{C}^{2} \mathrm{H}_{3}$ - Tramadol & Cambridge Isotope Laboratories (Andover, MA, USA) \\
\hline
\end{tabular}




\begin{tabular}{|c|c|c|c|c|}
\hline \multicolumn{5}{|c|}{$\begin{array}{c}\text { TABLE S2 } \\
\begin{array}{c}\text { Ionization mode, recoveries, relative standard deviation (RSD) and limit of } \\
\text { quantification (LOQ) of the pharmaceuticals }\end{array}\end{array}$} \\
\hline Pharmaceuticals & $\begin{array}{l}\text { Ionization } \\
\text { mode }\end{array}$ & $\begin{array}{c}\text { Recovery (average } \\
\text { of triplicate) } \\
\%\end{array}$ & $\begin{array}{c}\text { RSD } \\
\%\end{array}$ & $\begin{array}{l}\mathrm{LOQ} \\
\mathrm{ng} \cdot \ell^{-1}\end{array}$ \\
\hline Amitryptiline & HESI & 83.3 & 7.5 & 5 \\
\hline Atracurium & HESI & 85.8 & 7.2 & 0.5 \\
\hline Beclomethasone & HESI & 25.2 & 12.9 & 10 \\
\hline Biperiden & HESI & 106 & 8.4 & 0.1 \\
\hline Bisoprolol & HESI & 83.1 & 5.1 & 0.1 \\
\hline Bupropion & HESI & 96.3 & 4.7 & 0.1 \\
\hline Carbamazepine & HESI & 101 & 15.1 & 1 \\
\hline Cilazapril & HESI & 143 & 5.9 & 1 \\
\hline Citalopram & HESI & 83.6 & 8.5 & 5 \\
\hline Clomipramine & HESI & 72.7 & 11.4 & 0.5 \\
\hline Codeine & HESI & 86.7 & 24.0 & 0.5 \\
\hline Diclofenac & HESI & 42.1 & 4.4 & 10 \\
\hline Diltiazem & HESI & 107 & 3.8 & 0.5 \\
\hline Eprosartan & HESI & 62.3 & 4.3 & 5 \\
\hline Ethinyl estradiol & APPI & 85.7 & 4.1 & 10 \\
\hline Fexofenadine & HESI & 81.1 & 7.1 & 5 \\
\hline Fluconazole & HESI & 89.8 & 12.9 & 0.5 \\
\hline Fluoxetine & HESI & 97.0 & 11.4 & 5 \\
\hline Flutamide & HESI & 91.8 & 3.9 & 5 \\
\hline Haloperidole & HESI & 64.0 & 12.7 & 0.1 \\
\hline Hydroxyzine & HESI & 94.5 & 14.2 & 0.5 \\
\hline Ibuprofen & APPI & 62.4 & 7.4 & 10 \\
\hline Irbesartan & HESI & 109 & 2.6 & 0.5 \\
\hline Ketoprofen & APPI & 73.2 & 7.4 & 10 \\
\hline Levonorgestrel & APPI & 99.5 & 3.0 & 10 \\
\hline Loperamide & HESI & 61.6 & 15.7 & 0.5 \\
\hline Maprotiline & HESI & 84.1 & 7.4 & 5 \\
\hline Memantine & HESI & 85.7 & 7.7 & 0.5 \\
\hline Metoprolol & HESI & 82.9 & 1.3 & 5 \\
\hline Naproxen & APPI & 95.5 & 4.5 & 10 \\
\hline Orphenadrine & HESI & 94.7 & 11.2 & 0.1 \\
\hline Oxazepam & HESI & 97.4 & 1.1 & 5 \\
\hline Repaglinide & HESI & 93.4 & 8.6 & 0.5 \\
\hline Risperidone & HESI & 101 & 2.4 & 0.1 \\
\hline Rosuvastatin & HESI & 147 & 6.4 & 10 \\
\hline Sertraline & HESI & 71.2 & 16.5 & 10 \\
\hline Sulfamethoxazole & HESI & 97.3 & 4.3 & 5 \\
\hline Tramadol & HESI & 129 & 6.3 & 0.5 \\
\hline Trimethoprim & HESI & 109 & 10.7 & 0.1 \\
\hline Venlafaxine & HESI & 96.2 & 7.8 & 0.5 \\
\hline
\end{tabular}


http://dx.doi.org/10.4314/wsa.v40i1.20 Available on website http://www.wrc.org.za

ISSN 0378-4738 (Print) = Water SA Vol. 40 No. 1 January 2014 ISSN 1816-7950 (On-line) = Water SA Vol. 40 No. 1 January 2014 